\title{
Chemical and Sensory Characteristics of the Sparkling and Natural Ciders Stored in Different Types of Containers
}

\author{
Derek Plotkowski ${ }^{1}$, José Luis Aleixandre-Tudó ${ }^{2}$, José Luis Aleixandre ${ }^{2}$ \\ ${ }^{1}$ International Vintage Master, Ecole Supérieured'Agriculture, Angers (France) \\ ${ }^{2}$ Institute of Food Engineering for Development, Polytechnic University of Valencia (Spain)
}

\begin{abstract}
The cider industry is becoming more prolific in many parts of the world, and with the growing demand for cider comes a growing demand for high-quality ciders from traditional cider-growing regions. The main goal of the project was to study the chemical and sensory characteristics of the sparkling and natural ciders stored in different types of containers after three month of preservation at $23{ }^{\circ} \mathrm{C}$ in the temperature controlled storage room. Sparkling is a sweet, carbonated cider formulated for the export market, while the natural is a traditional dry and acidic cider, but appealing to cider enthusiasts. Both ciders wereput into different containers, including plastic kegs, beer bottles, and plastic bottles systems. Over the course of three months, samples were taken from the ciders and subject to chemical and sensory analyses for quality control, with kegs and glass bottles retaining cider quality well. Theresults show that plastic and metal kegs seem to have preserved Natural cider better than the control standard bottles, while plastic bottles system did a worse job preserving the cider. Beer bottles did a good job in preserving the cider, as well.
\end{abstract}

Keywords: Chemical parameters, sensory characteristics, sparkling cider, natural cider, types of containers.

\section{INTRODUCTION}

The traditional definition of cider is a beverage that results from the fermentation of apple juice, in practice it is a word whose definition changes based on your location. Different cider-producing countries have differing legal definitions of cider, with such variations as the potential inclusion of pear juice, the use of concentrates, the alcohol content, and even the minimum amount of apple juice legally required to use in the prefer-mentation mixture before a cider can legally be called a cider.Because of this, in certain markets there is much confusion over the term ciderand what it means.

In Spain, cider is defined as a drink resulting from the partial or total alcoholic fermentation of fresh apples or the juice(Ministerio de Agricultura, Pesca, y Alimentación, 1992). In France, the definition of cideris reserved for the beverage resulting from the fermentation of fresh apple must, with the possible use of pear must and up to 50\% concentrate.In the United Kingdom, the meaning ofcider is defined by the Alcoholic Liquor Duties Act of 1979, which states that the pre-fermentation mixture must consist of at least 35\% juice, to which any amount of sugar and water can be added (HM Revenue \& Customs, 2014).In the United States, the definition of hard cider is defined as a taxing category as a still wine derived from apples or apple concentrate and water, coming from at least $51 \%$ apple juice or concentrate and containing no more than $7 \%$ alcohol, after which it is legally a fruit wine, though "hard cider" can still appear on the label (Buckles, 2001). It should also be noted that in the United States, the word cider itself refers to freshly pressed apple juice that has not yet begun to ferment.In Canada, the definition of cider is the product of the alcoholic fermentation of apple juice, which allows for additions like yeast, sugar, concentrate, and preservatives(Justice Laws Website, 2015). The point of comparing these definitions is to show that cider can be a fundamentally different product in other countries.

The cider industry looks very different from those of wine, beer, and spirits. In the past, cider consumption was concentrated in traditional regions and countries of cider production, notably England, Northern Spain (Asturias and Basque Country), Northwest France (Brittany and Normandy), and Germany (Hessen). In recent years, interest in cider has increased in new markets, such as the United States, Canada, Belgium, and the Netherlands while production in these countries has lagged 
behind demand. This growth in cider consumption is particularly interesting for companies in Europe's traditional cider regions because what was once a regional, specialized product is now receiving international attention. This gives these companies the opportunity to expand their market to new countries. Many consumers in these new countries are looking for exciting, new, artisanal products, and the formerly hyper-regional cider fits the bill. In the market information section, these countries, as well as some traditional cider-consuming countries, will be examined.

Today, Asturias still produces over $80 \%$ of the cider in Spain, coming in at 60 million liters per year. In the 1980s, cider moved from a typically home-made product to an important industrial activity, with more than 1500 farms providing for over 100 natural cider producers in the principality. 85-95\% of that natural cider is consumed in the over 6000 cider bars in the country (Herrero Vazquez et al., 2014).

The goal of the study was to know the chemical and sensory characteristic of the sparkling and natural ciders stored in different types of select containers.

\section{MATERIALS AND METHODS}

This study took place at Asturias (Spain), one of the most important cider-producing regions in the world. Two lots of cider, one of natural cider and one of sparkling ciderwere bottled in a series of containers. After a set period, samples from each of the containers were taken and the cider was analyzed. Each category (each cider in a specific container stored for a specific amount of time) had three repetitions, except for the kegs that were left unopened until the end of the experiment, which had only one repetition.

The natural cideris fermented from $100 \%$ natural apple juiceat a controlled temperature in traditional chestnut wood barrels with natural yeasts. The cider typically has $6 \%$ alcohol by volume and is a blend of apple varieties. Each lot of natural cider is a unique blend that is tasted and tested by the cider producers. In each blend, they look for the balance of bitterness, acidity, and tannins.

Thesparkling cider have a maximum of 5.5\% alcohol as well as being carbonated and sweetened. Like the natural cider, it is fermented primarily in chestnut barrels. Its specific blend, along with the carbonation and added sugar, make for a fruity, sweet, refreshing, and bubbly cider.

The containers used for sparkling and natural ciders were plastic disposable kegs, beer bottles, and plastic bottles.

Some similar storage experiments have been done with other beverages, including two simulations of wine storage conditions (Ough, 1985; Robinson et al., 2010), a study of storage temperature on amine concentrations (Ough and Daudt, 1981), a study of wine in PET bottles (Ough, 1987), a study of temperature and dissolved oxygen on wine quality (Scott and Swaffield, 1997), and changes in volatile compounds in wine (Stern et al., 1975), and the influence of tannins and temperature during the storage of wines (Villamor et al., 2009). Not all of the studies studied the same thing as the cider experiment; however all had similar structures of repeated analyses at set intervals over a period of time.

All of the samples were filled directly from the kegging machine, either from the sample spigot or from the keg filling head. The tank of sparkling or naturalciders was attached to the machine and the cider was pumped into the machine, allowing it to fill the vessels. Plastic kegs, since they are sterile, were filled directly by the filling head. The beer bottles were filled from the sample spigot and capped with a hand capper. The bottles were cleaned with hot water before use. The plastic bottles were filled using the sample spigot and capped with the plastic caps with which they came. The bottles and caps were sterile and thus did not need cleaning.

When filling using the sample spigot, natural cider was easier to fill than sparkling cider, which produced a very large amount of foam due to the pressure from the filling machine. Due to the short storage time of the experiment, not much attention was paid to oxygen in the headspace of the containers. Although browning is less of a concern in cider than it is in wine, oxygen in the headspace is also associated with hydrogen sulfide smells and the loss of sulfur dioxide (Dimkou et al., 2011). In natural cider, where no sulfur dioxide is added, bottles are traditionally agitated after bottling in order to release carbon dioxide dissolved in the cider and act as a protectant in the headspace. 
Immediately after bottlingall of the containers were stored on the bottling room floor with the bottles heading out for shipment. They were transferred to be stored at $23{ }^{\circ} \mathrm{C}$ in the temperature controlled storage room. All of the containers were stored together. These conditions are constant, as opposed to a simulation of shipping conditions as done by Robinson et al. (2012), which showed that continuous exposure to elevated temperatures would damage the aromatic profile of the cider. According to some research, temperatures from $15-20^{\circ} \mathrm{C}$ are ideal for storage, while temperatures even at $25^{\circ} \mathrm{C}$ can be detrimental to a cider (Scott and Swaffield, 1998). For other factors, like pH and TA, storage temperature causes little change (Villamor et al., 2009).

For the bottled ciders, taking samples for analysis was as simple as opening the bottle and using the cider within. When a sample was needed from a keg, a tap with a movable head was attached to the keg. First, the connecting hose needed to be emptied of any cider from the previous keg, after which the cider from the keg of interestwas collected in a clean plastic $500 \mathrm{~mL}$ bottle from which samples could be easily taken.

Volatile acidity and the total acidity are measured using the García Tena method outlined by Mangas Alonso (2014). The ethanol content is measured by densitometry. The $\mathrm{pH}$ is measured using a CRISON micropH 2000. The free sulfur dioxide content is measured using the Ripper method(Iland, 2004). The polyphenol index and the reductive sugar are measuredusing Sidrascan (IR spectroscopy method).

Sensory Analysis is carried out by a trained tasters. Cider is served in an Asturian cider glass (base diameter $7.0 \mathrm{~cm}$, top diameter $9.0 \mathrm{~cm}$, height $12.0 \mathrm{~cm}$ ) at $23^{\circ} \mathrm{C}$. The temperature served is room temperature, despite cider normally being served at $10-12^{\circ} \mathrm{C}$, for the sake of consistency. Natural cider is served directly from its storage container into the glass, with an attempt at aeration, which is traditionally done by the "escanciar" method in Asturias (Spain). Sparkling cideris served as any other drink would normally be served. The tasters then use an organoleptic tasting sheet, as used by the Cider and Perry Academy (UK) to test the ciders sensory characteristics. Each cider was evaluated on all characteristics at the same time before waiting a short period and moving to the next period, a sequential monadic comparison (Colyar et al., 2009).

The majority of tests were one-way analysis of variance (ANOVA) with Tukey's post-test performed using GraphPadInStat version 3.10 forWindows (GraphPad Software, San Diego California USA, www.graphpad.com). Where applicable, repeated measure ANOVA statistical tests for significance with Tukey post-tests were run. For the laboratory analyses with repeated measurements and ANOVA was done comparing the results from the last trial for every reference with the results from the other references of the same cider style. Additionally, one-way ANOVAs were run for every individual category across the experimental period for each individual parameter to check if the change was significant. Finally, values that were measured lest frequently (initial and final), like reductive sugars and polyphenols, lactic acid, and malic acid, were analyzed by a paired t-test comparing the initial values to the final values. Statistical analyses were not carried out on the sensory data.

\section{RESUlTS}

Average values were rounded to appropriate significant figures based on the precision of the measurement of the raw data. Arithmetic means were used for all averages except for $\mathrm{pH}$, for which the average was calculated using the following equation:

Average $\mathrm{pH}=-\log _{10}\left[\left(\sum \mathrm{C}_{\mathrm{i})} /(\mathrm{n})\right]\right.$

Where $\mathrm{C}=\mathrm{pH}$ value of the sample; $\mathrm{n}=$ number of samples.

\subsection{Sparkling Cider}

\subsubsection{Sparkling Cider Stored in Plastic Keg}

The results of the chemical analyses over the course of three months, from the initial sparkling cider to the final sparkling cider in plastic kegs can be found in Table 1 . 
Table 1. Results of Chemical Analyses Over Three Months in Sparkling Cider Stored in Plastic Kegs.

\begin{tabular}{|c|c|c|c|c|c|c|c|c|}
\hline $\begin{array}{l}\text { Sparkling } \\
\text { Plastic Keg }\end{array}$ & 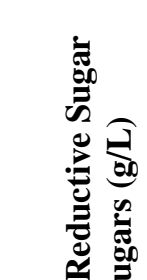 & 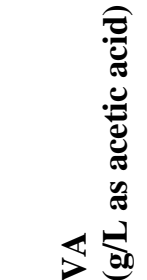 & 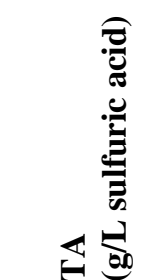 & 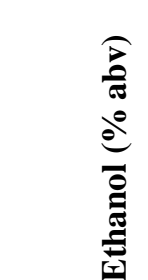 & 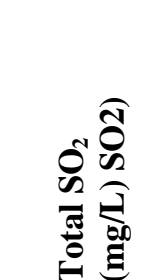 & 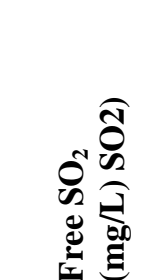 & $\frac{\pi}{2}$ & 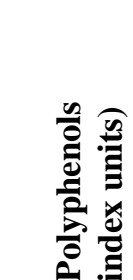 \\
\hline 0 Months & 7.10 & 1.36 & 4.2 & 5.2 & 50.1 & 41.6 & 3.51 & $18.32=$ \\
\hline 1 Month & - & 1.36 & 4.3 & 5.6 & 40.5 & 40.5 & 3.48 & - \\
\hline 2 Months & 6.98 & 1.34 & 4.4 & 5.4 & 65.1 & 39.5 & 3.31 & - \\
\hline 3 Months & 6.63 & 1.29 & 4.1 & 5.4 & 59.7 & 33.1 & 3.45 & 19.56 \\
\hline $\begin{array}{l}\text { Closed3 } \\
\text { Months }\end{array}$ & 6.85 & 1.35 & 4.2 & 5.3 & 60.8 & 35.2 & 3.43 & 18.5 \\
\hline
\end{tabular}

At the three-month mark, the sensory characteristics of the open and closed kegs were as follows. All of the ciders were clear, gold with green-white reflections, somewhat viscous, and produced foam. Respectively, the opened and closed keg ciders had average aromatic ratings of malic 6.33 and 6 , acetic 4.33 and 4, barnyard 1.67 and 2, fruitiness 8 and 8 , esters 8 and 8 , balsamic 2.67 and 3 , and citric 4.33 and 7. The average taste ratings were sweet 7 and 7 , acidic 6.33 and 6 , and bitter 2 and 2 . The body in both was medium thick with an astringency of one. The finish of both was a medium ten seconds of bitterness and lingering acidity. A comparison across time can be found in Figure 1.

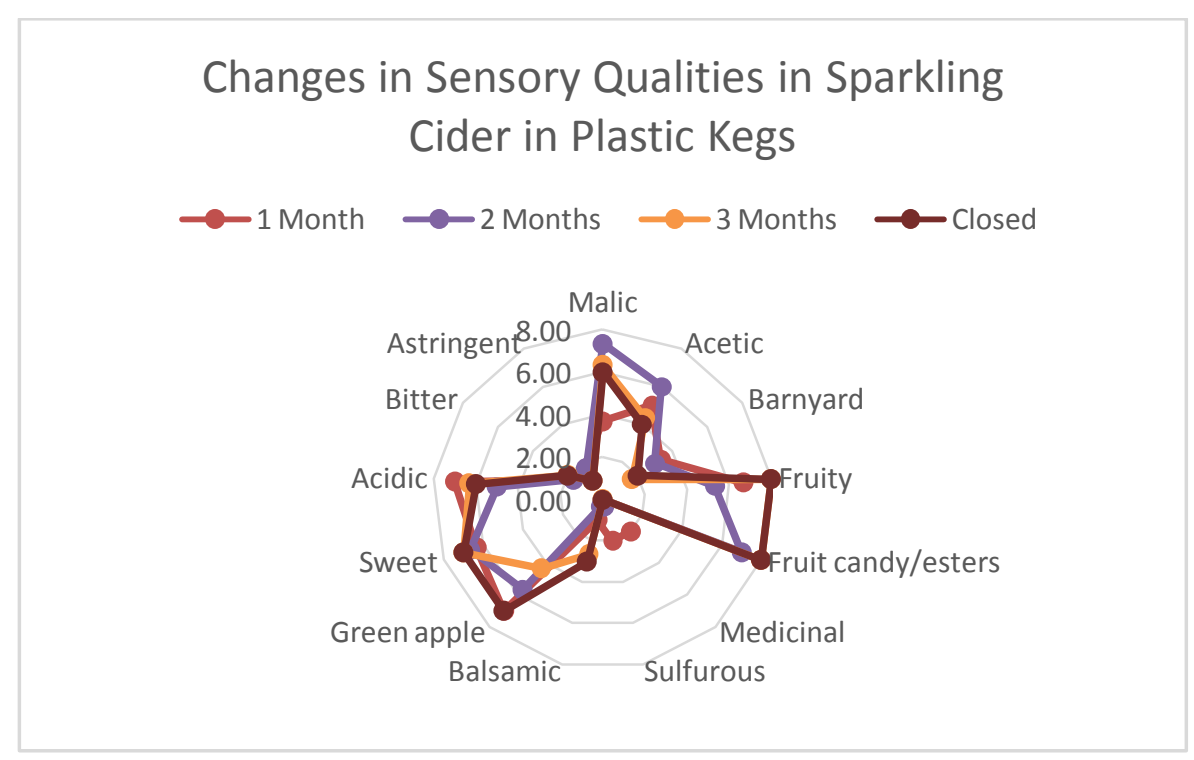

Figure 1. Changes in Sensory Qualities in Sparkling Cider in Plastic Kegs

\subsubsection{Sparkling Beer Bottle}

The results of the chemical analyses over the course of three months, from the initial sparkling cider to the final sparkling cider in beer bottles can be found in Table 2 .

Table 2. Results of Chemical Analyses Over Three Months in Sparkling Cider Stored in Beer Bottles.

\begin{tabular}{|c|c|c|c|c|c|c|c|c|}
\hline Sparkling Beer Bottle & 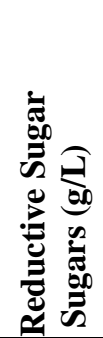 & 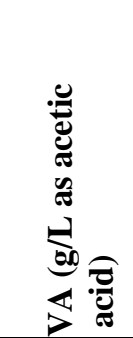 & 氕 & 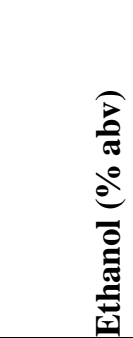 & 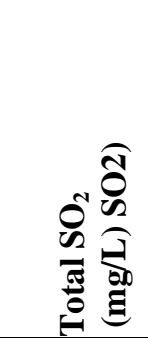 & 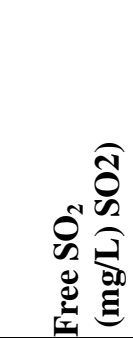 & $\frac{\pi}{2}$ & 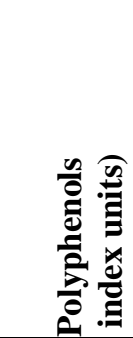 \\
\hline 0 Months & 7.10 & 1.37 & 3.80 & 5.5 & 48.0 & $35 . \overline{2}$ & - & 18.32 \\
\hline 1 Month & - & 1.39 & 4.4 & 5.5 & 34.1 & 35.2 & 3.55 & - \\
\hline 2 Months & 6.77 & 1.28 & 4.8 & 5.3 & 57.6 & 27.7 & 3.37 & - \\
\hline 3 Months & 6.70 & 1.21 & 4.4 & 5.3 & 54.4 & 26.7 & 3.39 & 19.51 \\
\hline
\end{tabular}


At the three month mark, the cider was perceived as clear, gold with green-white reflections, somewhat viscous, and having mousse. The average scores given for aromas were malic 6.00, acetic 4.33, barnyard 2.33, fruitiness 5.67, esters 7.33, balsamic 1.33, and green apple 5.67. The scores given for taste were sweet 6.67 , acidic 6.67 , and bitter 2.00 . The body was medium-to-medium-thick with an astringency score of 1.00 . The finish was fruity and lasted for 10 seconds. A comparison across time can be found in Figure 2.

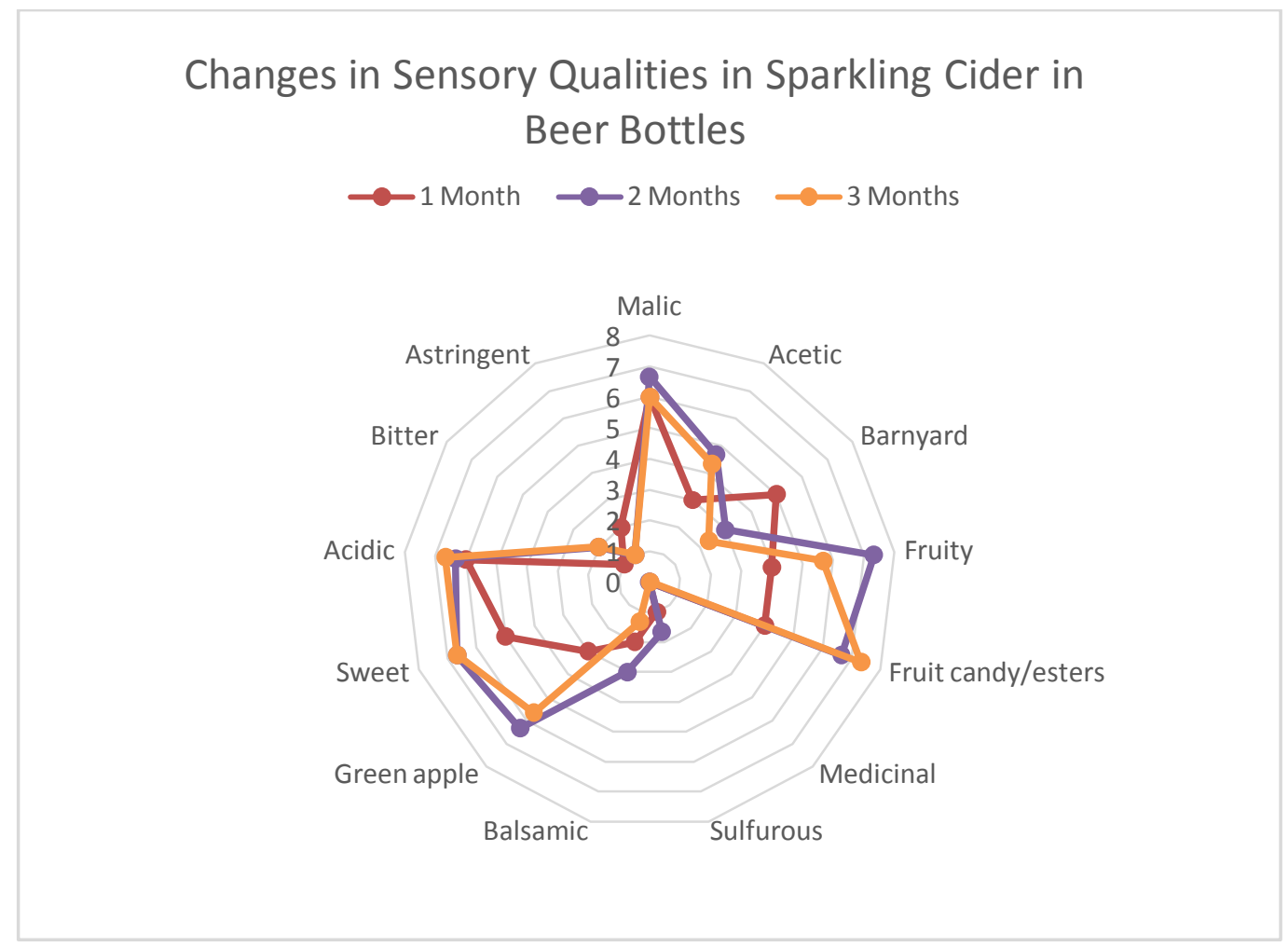

Figure 2. Changes in Sensory Qualities in Sparkling Cider in Beer Bottles.

\subsubsection{Sparkling Plastic Bottle}

The results of the chemical analyses over the course of three months, from the initial sparkling cider to the final sparkling cider in plastic bottles can be found in Table 3.

Table 3. Results of Chemical Analyses Over Three Months in Sparkling Cider Stored in Plastic Bottles.

\begin{tabular}{|c|c|c|c|c|c|c|c|c|}
\hline $\begin{array}{l}\text { Sparkling } \\
\text { Plastic } \\
\text { Bottle }\end{array}$ & 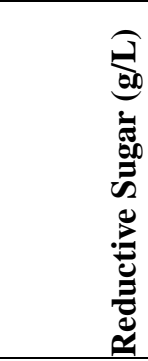 & 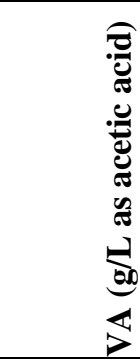 & 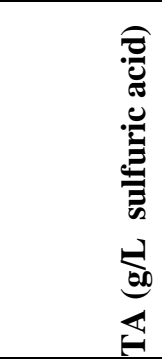 & 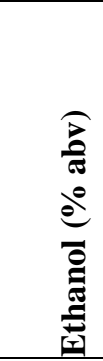 & 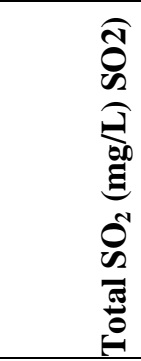 & శ్ & $\overline{2}$ & 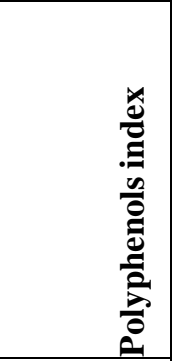 \\
\hline 0 Months & 7.10 & 1.37 & 3.80 & 5.5 & 48.0 & 35.2 & - & 18.32 \\
\hline 1 Month & - & 1.36 & 4.1 & 5.3 & 33.1 & 32.0 & 3.50 & - \\
\hline 2 Months & 6.98 & 1.26 & 4.6 & 5.4 & 54.4 & 25.6 & 3.37 & - \\
\hline 3 Months & 7.15 & 1.25 & 4.5 & 5.3 & 46.9 & 19.2 & 3.39 & 19.01 \\
\hline
\end{tabular}

At the three-month mark, the cider was perceived as clear, gold with green-white reflections, somewhat viscous, and being flat (no mousse or carbonation). The average scores given for aromas were malic 5.67, acetic 5.00, barnyard 2.67, fruitiness 6.00 , esters 7.67 , balsamic 3.00 , and green apple 6.00. The scores given for taste were sweet 6.00 , acidic 6.67 , and bitter 3.00 . The body was medium-thick with an astringency of 1.67. The finish was fruity and bitter and lasted for 10 seconds. A comparison over time can be found in Figure 3. 


\section{Changes in Sensory Qualities of Sparkling Cider in Plastic Bottles}

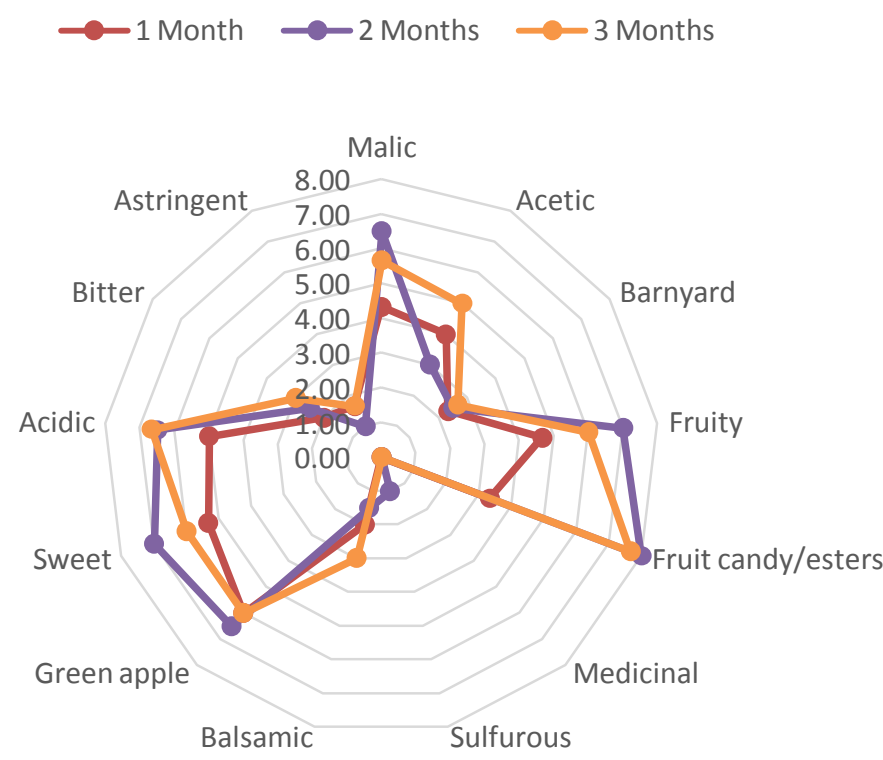

Figure 3. Changes in Sensory Qualities of Sparkling Cider in Plastic Bottles

\subsubsection{Sparkling Cider Statistics}

In general, Sparkling cider did not change much with regards to the laboratory analyses. In the analyses across the different containers after three months, the most important measurements did not show significant changes: volatile acidity $(\mathrm{p}=0.3599)$, total acidity $(\mathrm{p}=0.1441)$, and ethanol $(\mathrm{p}=0.5099)$. The $\mathrm{pH}$ showed a very significant difference $(\mathrm{p}<0.01)$, specifically between the plastic keg and the beer bottle control. The total $\mathrm{SO}_{2}(\mathrm{p}=0.0156)$ had a significant difference between the plastic keg and the plastic bottle, but neither was significantly different from the control. The free $\mathrm{SO}_{2}$ $(\mathrm{p}=0.0106)$ had a significant difference between the plastic keg and the champagne bottle, as well as between the plastic keg and the plastic bottle, but none were significantly different from the control.

\subsubsection{Sparkling Cider Plastic Keg}

In general, the plastic keg maintained the quality of Sparkling cider very well.

Chemical analysis. The volatile acidity of the cider at the end of the three months decreased over the course of the experiment, however the change was not significant $(\mathrm{p}=0.1329)$. The closed keg changed even less than the open keg did.The total acidity increased in both the closed and the opened kegs over the three months. However, the change over the period of the experiment was not significant $(\mathrm{p}=0.2038)$ and may be attributed to error.The $\mathrm{pH}$ decreased over the course of the three months in both the opened and the closed kegs. The decreases in the opened kegs were significant $(\mathrm{p}=0.0194)$ while the closed keg decreased by a similar amount.

The measured ethanol content decreased slightly over the course of the experiment in both the opened and the closed kegs. However, the change over the course of the experiment was not significant $(p=0.2228)$.The reductive sugar content decreased significantly $(0.0398)$ during the experimental phase in both the opened and the closed kegs.

The measured total $\mathrm{SO}_{2}$ content increased over the course of the experiment in both the opened and the closed kegs. The ANOVA showed that this change was very significant $(\mathrm{p}<0.0001)$ across all lengths of time.The measured free $\mathrm{SO}_{2}$ content decreased over the course of the experiment in both the opened and the closed kegs. These results were very significant $(\mathrm{p}=0.0061)$.

The change in polyphenol index from the initial cider to the final cider was significant $(\mathrm{p}=0.0152)$. This change was much greater in the open kegs than the closed keg. 
Sensory Analysis. The visual aspect of the cider largely remained unchanged throughout the course of the experiment, with the cider maintaining its clarity, its gold-brown color with green-white reflections, its strong foaming, and slight viscosity.

The sensory profile of the closed cider is very similar to that of the opened kegs. In the opened kegs, the malic, fruity, ester, and balsamic characteristics increased over time. The acetic, barnyard, medicinal, sulfurous, and green-apple aromas decreased in the three months.

After three months, the ciders were perceived as slightly sweeter, slightly more bitter, and slightly less acidic than at the beginning of the experiment.

\subsubsection{Sparkling cider Beer Bottle}

The beer bottle is the typical container used for Sparkling cider, and thus is being used as a control for the experiment.

Chemical analysis. The volatile acidity decreased over the course of the experiment, and the results were extremely significant ( $\mathrm{p}=0.017$ ), particularly between the initial cider and the third month, the first and second month, and between the first and third month. The total acidity increased as the experiment progressed, however the results were not considered significant.The $\mathrm{pH}$ decreased as the experiment progressed, results that were considered to be extremely significant $(\mathrm{p}<0.0001)$.

The ethanol content decreased over the course of the experiment, however the results were not considered significant. The reductive sugar content decreased as the experiment progressed.

The measured total $\mathrm{SO}_{2}$ was higher at the end of the experiment than at the beginning, results which were extremely significant $(\mathrm{p}<0.0001)$. The measured free $\mathrm{SO}_{2}$ was lower at the end of the experiment than at the beginning, which was very significant $(\mathrm{p}=0.0052)$.

The polyphenolic index increased over the course of the experiment.

Sensory Analysis. The color, clarity, viscosity, and carbonation did not change throughout the three months of the experiment. The cider was persistently very clear, gold with green-white reflections, bubbly, and with an aqueous to slightly viscous viscosity.Malic and balsamic aromas were mostly stable throughout the experiment. Acetic, fruity, ester, and green apple aromas increased between the first and third months. Barnyard and sulfurous smells decreased with time.The sweetness, acidity, and bitterness all increased slightly over the course of the three months. The body maintained a round, slight thickness and low astringency. The aftertaste was long at first, but decreased to a medium length over time with a dried fruit and nutty flavor.

\subsubsection{Plastic Bottle}

Although most of the analytical measurements were reasonable, the cider lost most of its carbonation and many sensory characteristics.

Chemical analysis. The volatile acidity decreased over the course of the experiment, with changes considered to be extremely significant $(\mathrm{p}=0.0002)$, particularly between the initial cider and the second and third months as well as between the first month and the second and third months.The total acidity increased over the course of the experiment, although the change was considered to be not quite significant ( $\mathrm{p}=0.0804)$. The $\mathrm{pH}$ decreased over the course of the three months.

The ethanol content decreased significantly $(\mathrm{p}=0.0230)$ over the course of the experiment between the initial cider and the third month.The reductive sugars decreased slightly over the course of the three months.

The measured total $\mathrm{SO}_{2}$ varied over the course of the experiment, but it ultimately maintained about the same value. The changes, however, were very significant $(\mathrm{p}=0.0049)$, particularly between the values after the first month and all other values.The measured free $\mathrm{SO}_{2}$ decreased over the course of the experiment, the change being very significant $(\mathrm{p}=0.0060)$ between the initial cider and the first and third months.

The polyphenolic index increased over the course of the three months.

Sensory Analysis The color and clarity did not change over the course of the experiment. From the beginning, the cider was gold with white-green reflections and perfectly clear. At one month, the cider 
had some bubbles, but by the second month was almost completely flat.Generally, the aromatic characteristics strengthened, even if slightly, between the first and third month, including malic, acetic, barnyard, fruity, ester, and balsamic flavors. Green apple characteristics were consistently of medium-high strength.All of the basic flavors strengthened over the three months, with the cider being perceived as sweeter, more acidic, and bitterer than each of the previous samples. The body was a consistent round, medium-thick with low astringency. The aftertaste ranged from short to medium length and was mostly bitter with some dried fruit tones.

\subsection{Natural Cider}

\subsubsection{Natural Cider Plastic Keg}

The results of the chemical analyses over the course of nine weeks, from the initial Natural cider to the final Natural cider in plastic kegs can be found in Table 4.

Table 4. Results of Chemical Analyses Over 9 Weeks in Natural Cider Stored in Plastic Kegs

\begin{tabular}{|c|c|c|c|c|c|c|c|c|}
\hline Natural Plastic Bottle & 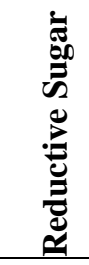 & 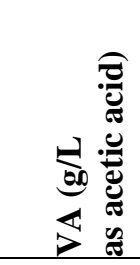 & 矛 & 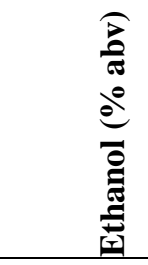 & 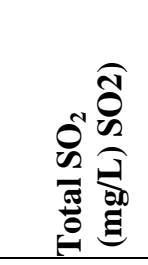 & 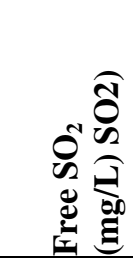 & 굴 & 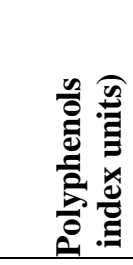 \\
\hline 0 Weeks & $<.01$ & 1.05 & 3.43 & 6.1 & & & 3.77 & 14.06 \\
\hline 2 Weeks & $<.01$ & 0.95 & 3.8 & 6 & 9.6 & 12.8 & 3.60 & \\
\hline 3 Weeks & $<.01$ & 0.88 & 3.8 & 6.0 & 12.8 & 11.7 & 3.43 & \\
\hline 6 Weeks & $<.01$ & 1.13 & 3.9 & 5.9 & 9.6 & 8.5 & 3.51 & \\
\hline 9 Weeks & $<.01$ & 1.10 & 3.9 & 6.0 & 10.7 & 7.5 & 3.58 & 14.50 \\
\hline Closed 9 Weeks & $<.01$ & 1.15 & 3.8 & 6 & 9.6 & 6.4 & 3.58 & 14.6 \\
\hline
\end{tabular}

After nine weeks, the sensory characteristics of the open and closed plastic kegs were as follows. All of the ciders were somewhat cloudy, gold with green-white reflections, somewhat viscous, and produced mousse. Respectively, the opened and closed keg ciders had average aromatic ratings of: malic 6.33 and 6, acetic 5.33 and 5, barnyard 2.67 and 2, fruitiness 7 and 7, esters 7.33 and 8, balsamic 2.67 and 4, and green apple 6 and 8 . The average taste ratings were sweet 3.33 and 3, acidic 7 and 8 , and bitter 3 and 3. The body in both was medium light with an astringency of 2.33 and 2, respectively. The finish of both was a medium ten seconds of bitterness and lingering acidity. The sensory changes over time can be seen in Figure 4.

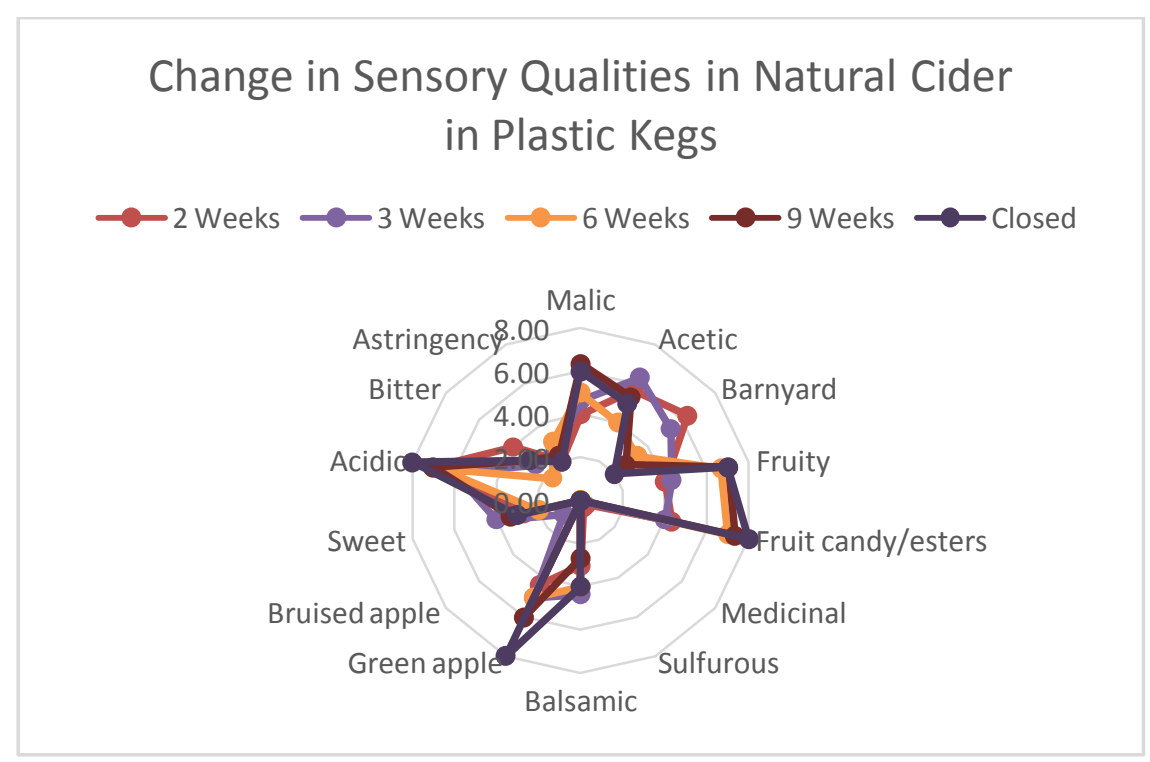

Figure 4. Changes in Sensory Qualities in Natural Cider in Plastic Kegs

\subsubsection{Natural Cider in Beer Bottle}

The results of the chemical analyses over the course of nine weeks, from the initial natural cider to the final natural cider in beer bottles can be found in Table 5 . 
Table 5. Results of Chemical Analyses Over 9 Weeks in Sidra Natural Stored in Beer Bottles

\begin{tabular}{|c|c|c|c|c|c|c|c|c|}
\hline Natural, Beer Bottle & 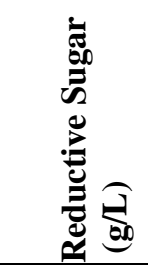 & 氕 & 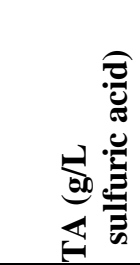 & 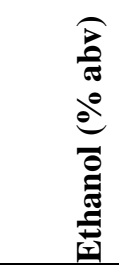 & 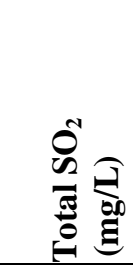 & 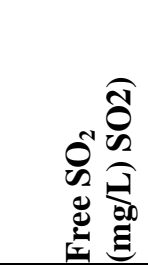 & 졸 & 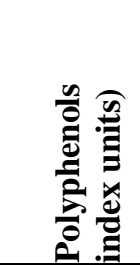 \\
\hline o Weeks & $<.01$ & 1.05 & 3.43 & 6.1 & - & - & 3.77 & 14.06 \\
\hline 3 Weeks & $<.01$ & 0.99 & 3.6 & 6.1 & 8.5 & 9.6 & 3.61 & - \\
\hline 6 Weeks & $<.01$ & 1.16 & 3.7 & 5.9 & 12.8 & 12.8 & 3.60 & - \\
\hline 9 Weeks & $<.01$ & 0.93 & 3.7 & 6.0 & 9.6 & 7.5 & 3.42 & 13.73 \\
\hline
\end{tabular}

Sensory Analysis: At the nine week mark, the cider was perceived as somewhat hazy, gold with green-white reflections, somewhat viscous, and having mousse. The average scores given for aromas were malic 5.67, acetic 5.33, barnyard 2, fruitiness 7, esters 7, balsamic 2.33, and green apple 5.67. The scores given for taste were sweet 3.00, acidic 7, and bitter 2.33 . The body was medium-light with an astringency score of 1.67. The finish was bitter and lasted a medium-short length of about seven seconds. The sensory changes over time can be seen in Figure 5.

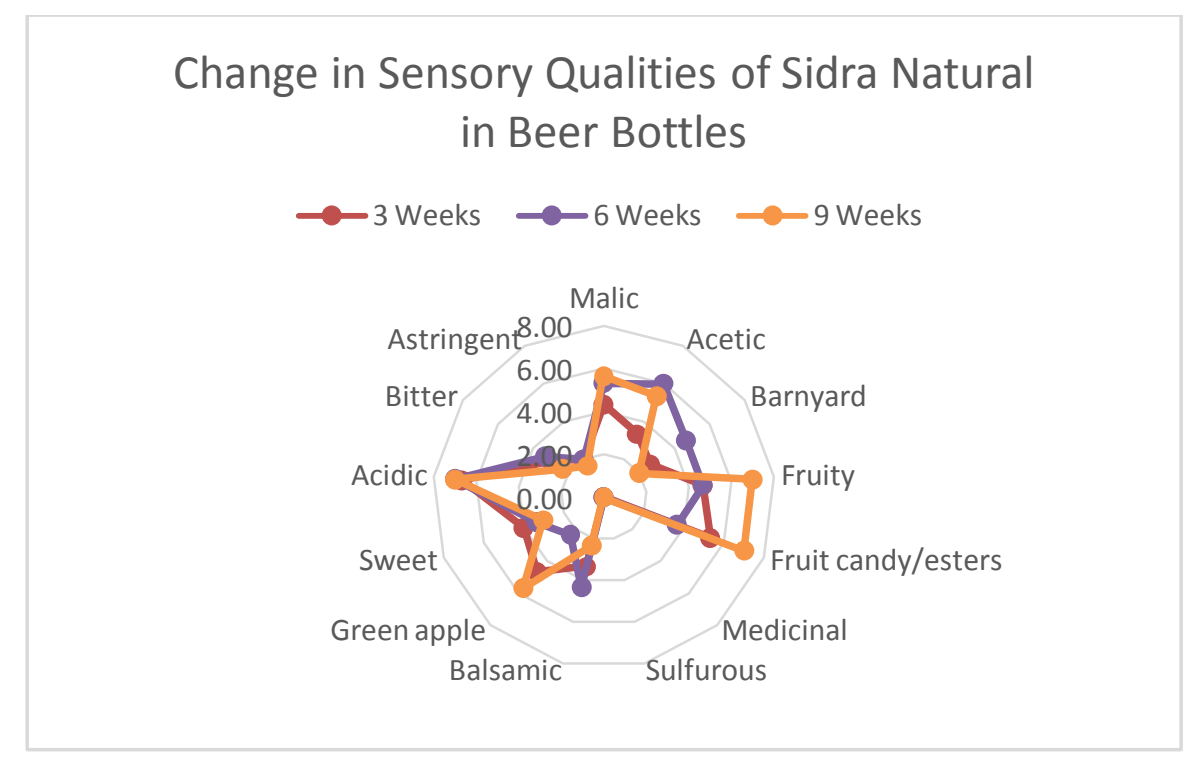

Figure 5. Changes in Sensory Qualities in Natural Cider in Beer Bottles

\subsubsection{Natural Cider Plastic Bottle}

The results of the chemical analyses over the course of nine weeks, from the initial natural cider to the final natural cider in in plastic bottles can be found in Table 6 .

Table 6. Results of Chemical Analyses Over 9 Weeks in Natural Cider Stored in Plastic Bottles.

\begin{tabular}{|c|c|c|c|c|c|c|c|c|}
\hline Natural, Plastic Bottle & 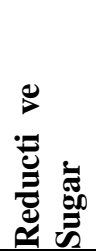 & 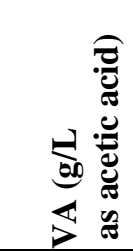 & 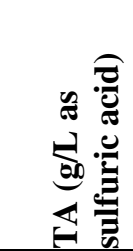 & 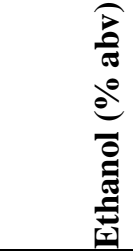 & 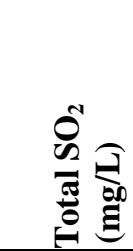 & 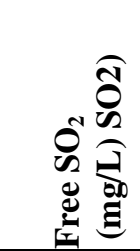 & $\sqrt{2}$ & 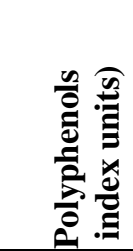 \\
\hline o Weeks & $<.01$ & 1.05 & 3.43 & 6.1 & - & - & 3.77 & 14.06 \\
\hline 3Weeks & $<.01$ & 0.97 & 3.8 & 6.0 & 10.7 & 9.6 & 3.54 & - \\
\hline 6 Weeks & $<.01$ & 1.52 & 3.8 & 5.9 & 9.6 & 9.6 & 3.57 & - \\
\hline 9 Weeks & $<.01$ & 1.19 & 9.3 & 4.5 & 9.6 & 9.6 & 3.33 & 19.01 \\
\hline
\end{tabular}

At the nine-week mark, the unspoiled cider was perceived as somewhat hazy, gold with green-white reflections, somewhat viscous, and having mousse. The scores given for aromas were malic 7, acetic 5 , barnyard 2 , fruitiness 6 , esters 5 , balsamic 2 , and green apple 7 . The scores given for taste were sweet 3 , acidic 7 , and bitter 4 . The body was medium with an astringency score of 2 . The finish was 
bitter and lasted for a medium-long 15 seconds. The spoiled ciders were rated at 9 in acetic aromas, ester aromas, and bruised apple aromas in addition to a 9 rating in acidity and 4.5 in sweetness. They had a thick body with a medium-long vinegary aftertaste. The sensory changes over time (excluding the spoiled ciders) can be seen in Figure 6.

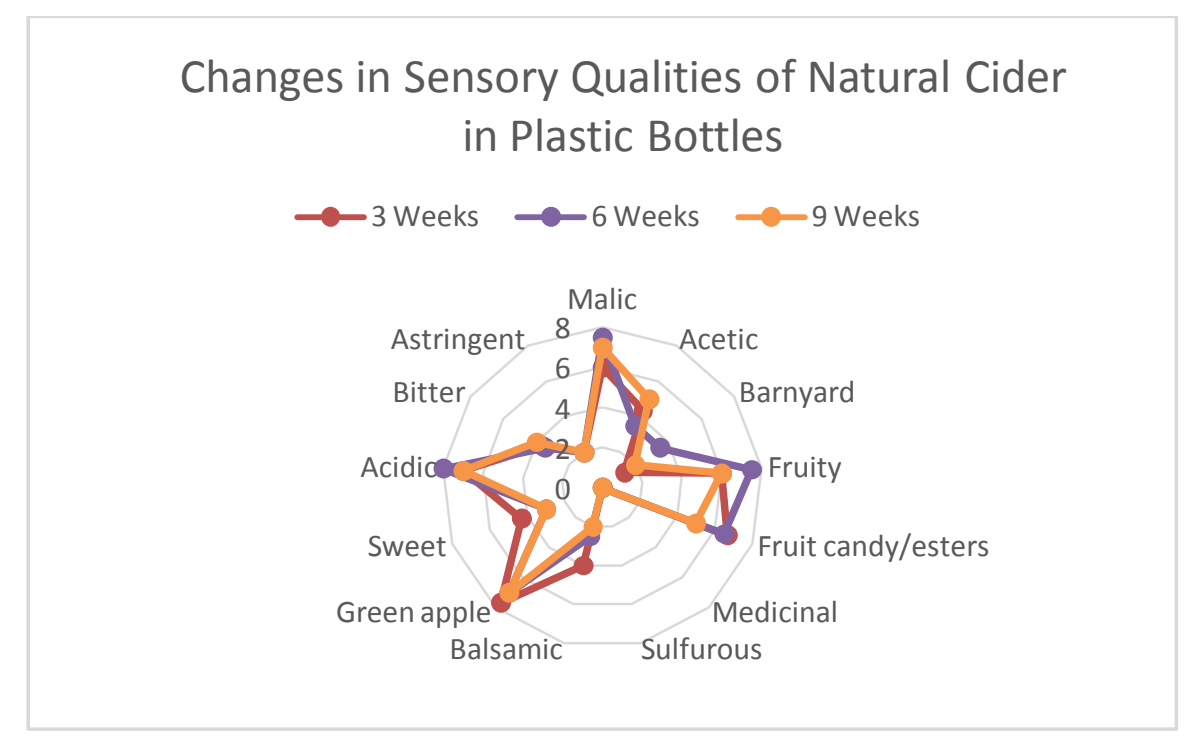

Figure 6. Changes in Sensory Qualities of Natural Cider in Plastic Bottles

\subsubsection{Natural Cider Statistics}

In general, Natural cider did not change much with regards to the laboratory analyses, although specific containers did. In the analyses across the different containers after nine weeks, the most important measurements did not show significant changes: volatile acidity $(\mathrm{p}=0.0628)$, total acidity $(\mathrm{p}=0.0867)$, and ethanol $(\mathrm{p}=0.0751)$. The $\mathrm{pH}$ showed an extremely significant difference $(\mathrm{p}=0.0009)$, specifically between the plastic bottle and plastic keg. These $\mathrm{pH}$ values werenot significantly different from the standard bottle control however. Neither the total $\mathrm{SO}_{2}(\mathrm{p}=0.4582)$ nor the free $\mathrm{SO}_{2}$ $(\mathrm{p}=0.2762)$ showed any significant differences across the board. The change in polyphenolic index over the course of the experiment was not considered to be significant $(\mathrm{p}=0.4202)$, but the general decrease in lactic acid content was very significant $(\mathrm{p}=0.0019)$ and the decrease in malic acid content was extremely significant $(\mathrm{p}=0.0003)$.

\subsubsection{Sidra Natural Plastic Keg}

In the plastic kegs, the quality of the cider was generally retained.

Chemical analysis. The volatile acidity of the cider in plastic kegs generally increased over time, with a significant change $(\mathrm{p}=0.0388)$ between the third week and the sixth week. The total acidity increased between the initial cider and the kegged cider, but once it was kegged it remained relatively stable. The change was considered to be significant $(\mathrm{p}=0.0007)$. The $\mathrm{pH}$ decreased over time in both the opened and the closed kegs.

The ethanol content decreased slightly in both the opened and the closed kegs, a very significant change ( $\mathrm{p}=0.0091)$ particularly between the initial cider and the third and sixth weeks. The reductive sugars did not change at all.

The total $\mathrm{SO}_{2}$ did not change greatly in either the opened or the closed kegs, but the change from the third week to the sixth week in the open keg was significant $(\mathrm{p}=0.0494)$. The free $\mathrm{SO}_{2}$ decreased slightly in both the opened and the closed kegs, but the changes were not significant.

The polyphenolic indices were higher in both the opened and closed kegs than the initial values.

Sensory Analysis.There werenot many differences between the closed keg and the kegs left open for nine weeks.The color and clarity was consistent throughout the entire experiment, with the cider being slightly cloudy and having a gold-green color. The cider was consistently aqueous to slightly viscous and was able to form a nice mousse when poured.Certain characteristics increased over time, including malic, fruity, ester, and green apple aromas. Barnyard aromas decreased greatly over time and balsamic aromas decreased slightly. One sample from an open keg had a bruised apple 
aroma.Sweetness slightly increased during the time of the experiment, while acidity stayed constant and bitterness decreased.The body of the cider remained medium-light throughout the experiment, and astringency did not change much. The medium-length bitter aftertaste was also the same across the board.

\subsubsection{Sidra Natural Beer Bottle}

Although the cider changed quantifiably during the course of the study, it retained its quality.

Chemical analysis. The volatile acidity decreased between the initial bottling and the final test, although the volatile acidity level was higher at the six week mark than at any other point. That being said, the changes in volatile acidity were not significant.The total acidity increased throughout the course of the study, but the changes were not significant. The $\mathrm{pH}$ decreased over the course of the study, with a significant change between the third and the ninth weeks $(\mathrm{p}=0.0294)$.

The ethanol content decreased over the course of the study, showing a very significant change $(\mathrm{p}=0.0014)$ between the initial cider and the sixth and ninth weeks. There was no change in reductive sugar content over the course of the study.

The total $\mathrm{SO}_{2}$ content did not vary much over the course of the study, yet the changes between the third and the sixth week and the sixth and the ninth week were very significant $(\mathrm{p}=0.0066)$. The free $\mathrm{SO}_{2}$ content did not vary much over the course of the study, yet the changes between the third and the sixth week and the sixth and the ninth week were very significant $(\mathrm{p}=0.0025)$.

The polyphenolic index was lower after nine weeks in the beer bottle than they were in the initial cider.

Sensory Analysis.The clarity and color generally did not change (the exception being when the sample being tasted was the bottom of the bottle, which in cider usually has a lot of sediment). The product at nine weeks was slightly more viscous than at six.Over the nine weekperiod, malic, acetic, fruity, ester, and green apple aromas increased, while barnyard and balsamic aromas decreased. Some aromas peaked at six weeks, like acetic, barnyard, and balsamic, while other flavors reached a low point at six weeks, like green apple and esters.Generally, sweetness decreased with time, acidity remained constant, and bitterness decreased.The body was variable, with some bottles having a slight thickness and others a lighter body. Astringency was consistently low during the entire experiment. The finish was medium short (about 7s) across the entire timeframe, with a consistent bitter aftertaste.

\subsubsection{Sidra Natural Plastic Bottle}

In plastic bottles, there was spoilage in three of the nine samples, one after 6 weeks and two after 9 weeks. These spoiled samples had visible bacterial growth in addition to altered analytical values. There was also a noted loss of gas upon the opening of the bottles. In the future, perhaps non-intrusive methods of sterilization could be explored to prevent this kind of spoilage. Azhuvalappil et al.(2010)wrote about using pulsed electric fields and UV treatments to preserve fresh apple juice and increase safety by reducing bacterial populations. These methods do not have the same organoleptic effects that heat pasteurization has and could perhaps be explored to prevent bacterial spoilage in natural cider (Azhuvalappil et al., 2010).

Chemical analysis. If the spoiled samples are excluded, the volatile acidity increased slightly over the 9 weeks. The three spoiled samples had greatly elevated values of volatile acidity, with two samples, 63 and 65 , requiring more $\mathrm{NaOH}$ to titrate than the buret used in the analysis could hold. The total acidity did not change much over the course of the study;howeverthe two spoiled samples at the nine week mark had a greatly elevated total acidity. The $\mathrm{pH}$ decreased slightly over time. The spoiled nineweek samples, however, had a much lower $\mathrm{pH}$ than the unspoiled sample.

The ethanol content of the samples did not change much over the nine weeks. The spoiled samples had greatly reduced ethanol content.The reductive sugars did not change over the course of the experiment.

The total and free $\mathrm{SO}_{2}$ content was not changed over the course of the study.

The unspoiled sample had a lower polyphenolic index than the initial cider, but the index in the spoiled cider skyrocketed, with one sample have an index over twice as high as the initial cider. 
Sensory Analysis.In the unspoiled ciders the color, clarity and viscosity did not change. The spoiled ciders browned over the nine weeks. None of the ciders retained much gas and thus did not produce much mousse.Among the unspoiled ciders, many aromas peaked at six weeks before falling at the nine week mark, including fruit, barnyard aroma, and malic aroma. Green apple, ester, and balsamic flavors decreased with time. The acetic characteristic dropped after six weeks but was stronger at week nine. The spoiled ciders produced overpowering acetic and fruity-esters smells.For the unspoiled ciders, the perception of sweetness decreased over time, while acidity remained stable and bitterness slightly increased. The spoiled ciders had a higher perceived sweetness. The nine-week spoiled ciders also had a lower bitterness and much higher acidity than any of the others. The body of the cider thickened slightly over time, but the astringency remained unchanged. The finish was consistently medium to medium-long with a bitter aftertaste in the unspoiled ciders.

\section{DISCUSSION}

Table 7 shows a brief comparison of which changes were considered significant across the different containers and measurements in Sparkling cider.

Table 7. Overview of changes in Sparkling cider

\begin{tabular}{|c|c|c|c|c|c|c|c|c|c|}
\hline $\begin{array}{l}\text { Sparkling cider } \\
\text { Significance }\end{array}$ & $\overleftrightarrow{s}$ & 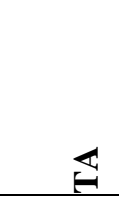 & $\frac{\pi}{2}$ & $\underset{\mathscr{R}}{\tilde{H}}$ & $\begin{array}{l}\text { O } \\
\mathscr{N} \\
\text { I }\end{array}$ & 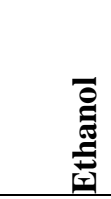 & $\begin{array}{l}\frac{n}{0} \\
\frac{0}{2} \\
\frac{2}{0} \\
\end{array}$ & 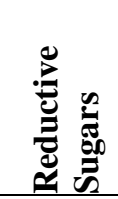 & 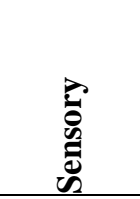 \\
\hline Beer Bottle (control) & sig & $n s$ & sig & Sig & sig & $n s$ & $n / a$ & $n / a$ & positive \\
\hline Plastic Keg & ns & ns & Sig & Sig & sig & $\mathrm{ns}$ & $\mathrm{n} / \mathrm{a}$ & $\mathrm{n} / \mathrm{a}$ & Positive \\
\hline Plastic Bottle & sig & ns & Ns & Sig & sig & sig & $\mathrm{n} / \mathrm{a}$ & $\mathrm{n} / \mathrm{a}$ & Negative \\
\hline General (3 months) & $n s$ & $n s$ & sig & Sig & sig & $n s$ & Sig & Sig & $n / a$ \\
\hline
\end{tabular}

Based on this table, plastic kegs seem to have preserved Sparkling cider better than the control beer bottles, while plastic bottles did a worse job preserving the cider. Champagne bottles did a serviceable job in preserving the cider, but did not retain the positive sensory profile that the keg and beer bottle did. That being said, among the most important parameters (volatile acidity, total acidity, and ethanol content) there werenot any significant changes between the different containers after three months. Moving forward into the recommendations, beer bottles and plastic kegs will be considered as good options. Champagne bottles should be subjected to further review, but cannot be recommended at this time. Plastic bottles are not recommended, but should any new developments come about they should be reconsidered.

Table 8 shows a brief comparison of which changes were considered significant across the different containers and measurements in natural cider.

Table 8. Overview of changes in Natural cider.

\begin{tabular}{|c|c|c|c|c|c|c|c|c|c|c|}
\hline $\begin{array}{l}\text { Natural cider } \\
\text { Significance }\end{array}$ & 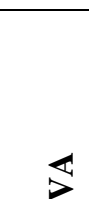 & 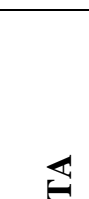 & 졸 & $\overbrace{\mathscr{L}}^{\sigma}$ & 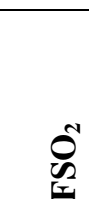 & & $\begin{array}{l}\frac{n}{0} \\
\frac{0}{0} \\
\frac{1}{2} \\
\frac{2}{0}\end{array}$ & 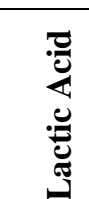 & 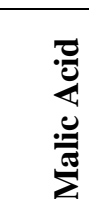 & 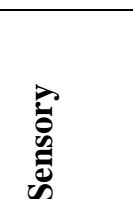 \\
\hline Standard Bottle (control) & Sig & sig & $N s$ & $\mathrm{Ns}$ & Ns & Ns & $n / a$ & $n / a$ & $n / a$ & positive \\
\hline Metal Keg & Ns & Sig & Ns & Sig & Ns & Ns & $\mathrm{n} / \mathrm{a}$ & $\mathrm{n} / \mathrm{a}$ & $\mathrm{n} / \mathrm{a}$ & positive \\
\hline Plastic Keg & Sig & Ns & Ns & Sig & Ns & Sig & $\mathrm{n} / \mathrm{a}$ & $\mathrm{n} / \mathrm{a}$ & $\mathrm{n} / \mathrm{a}$ & positive \\
\hline Bag-in-Box & Sig & Ns & Sig & Ns & Ns & Sig & $\mathrm{n} / \mathrm{a}$ & $\mathrm{n} / \mathrm{a}$ & $\mathrm{n} / \mathrm{a}$ & negative \\
\hline Beer Bottle & Ns & Ns & Sig & Sig & sig & Sig & $\mathrm{n} / \mathrm{a}$ & $\mathrm{n} / \mathrm{a}$ & $\mathrm{n} / \mathrm{a}$ & positive \\
\hline Plastic Bottle & Ns & Ns & Sig & Ns & Ns & Ns & $\mathrm{n} / \mathrm{a}$ & $\mathrm{n} / \mathrm{a}$ & $\mathrm{n} / \mathrm{a}$ & negative \\
\hline General (9 weeks) & $N s$ & Ns & Sig & Ns & Ns & $\mathrm{ns}$ & $N s$ & Sig & Sig & $n / a$ \\
\hline
\end{tabular}

Based on this table, plastic and metal kegs seem to have preserved Natural cider better than the control standard bottles, while plastic bottles system did a worse job preserving the cider. Beer bottles did a good job in preserving the cider, as well. That being said the only significant change among the values across all of the containers after nine weeks was $\mathrm{pH}$, specifically between the plastic bottle and the opened containers (kegs and bag-in-box). Moving forward into the recommendations, plastic kegs, metal kegs, standard bottles, and beer bottleswill be considered as good options. Plastic bottles systemare not recommended, but should any new developments come about they should be reconsidered. 


\section{REFERENCES}

[1] AICV. 2014. "European Cider Trends 2014." European Cider and Fruit Wine Association.

[2] Azhuvalappil, Zareena, Xuetong Fan, David J Geveke, and Howard Q Zhang. 2010. "Thermal and nonthermal processing of apple cider: storage quality under equivalent process conditions." Journal of Food Quality 33 (5):612-631.

[3] Buckles, B. 2001. "Hard Cider, Semi-Generic Wine Designations, and Wholesale Liquor Dealers' Signs (97-2523).” Federal Register. https://www.federalregister. gov/articles/2001 /11/26/01-29361/hard-cider-semi-generic-wine-designations-and-wholesale-liquor-dealers-signs97-2523\#h-10(retrieved September 14, 2015).

[4] Colyar, Jessica M, Dennis L Eggett, Frost M Steele, Michael L Dunn, and Lynn V Ogden. 2009. "Sensitivity Comparison of Sequential Monadic and Side-by-Side Presentation Protocols in Affective Consumer Testing." Journal of food science 74 (7):S322-S327.

[5] ConsejoRegulador Sidra de Asturias. 2015 (1). "Tipos de Sidra." Sidra de Asturias. http://www.sidradeasturias.es/detalle.php?var=61\&vari=59\&\%20vari2=61(retrieved September 14, 2015).

[6] Consejo Regulador Sidra de Asturias. 2015 (2). "Variedades de Manzana." Sidra de Asturias. http://www.sidradeasturias.es/detalle.php?var $=55 \&$ vari $=54 \& \% 20$ vari2 $=55$ (retrieved September 14, 2015).

[7] Cider Market LLC. 2015. "Germany Import." The Cyder Market. https://cydermarket .com/Germany_Import.html (retrieved September 14, 2015).

[8] Dimkou, Evdokia, Maurizio Ugliano, Jean Baptiste Dieval, Stéphane Vidal, Olav Aagaard, Doris Rauhut, and Rainer Jung. 2011. "Impact of Headspace Oxygen and Closure on Sulfur Dioxide, Color, and Hydrogen Sulfide Levels in a Riesling Wine." American Journal of Enology and Viticulture 62 (3):261-269. doi: 10.5344/ajev.2011.11006.

[9] Direction Générale des Douanes et Droits Indirects (France). 2013. "Boissons fermentées." Douane.gouv.fr. http://www.douane.gouv.fr/articles/a10952-boissons-fermentees (retrieved September 13, 2015).

[10] Euromonitor International(2015). "Cider/Perry in Belgium (Canadá, Germany, Netherlands, United Kingdom, and United States): Executive Summary." http://www.euromonitor.com/ciderperry-in-belgium (canada, germany, netherlands, united-kingdom, us)/report (retrieved September 14, 2015).

[11] Garai-Ibabe, Gaizka, Ana Irastorza, María Teresa Dueñas, Pedro J. Martín-Álvarez, and Victoria M. Moreno-Arribas. 2013. "Evolution of amino acids and biogenic amines in natural ciders as a function of the year and the manufacture steps." International Journal of Food Science \& Technology 48 (2):375-381. doi: 10.1111/j.1365-2621.2012.03198.x.

[12] Gonzalez San José, M.L. 2014. La evaluación sensorial. In: Blanco Gomis, D. and Mangas Alonso, J.J. eds. La manzana y la sidra: bioprocesos, tecnologías de elaboración y control. Universidad de Oviedo, pp. 137-176.

[13] Grier, K., Sweetland, J., and Rajcan, I. 2013. "Economic Impact Study for the Ontario Hard Cider Industry Final Report." George Morris Center, Guelph, Ontario, Canada.

[14] Herrero Vazquéz, M., Gonzalo Vergara, A., and García Díaz, L.A. 2014. Tecnología de la elaboración de sidra. Equipamento industrial. In: Blanco Gomis, D. and Mangas Alonso, J.J. eds. La manzana y la sidra: bioprocesos, tecnologías de elaboración y control. Universidad de Oviedo, pp. 197-220.

[15] HM Revenues and Customs. 2014. "Excise Notice 162: Cider Production." Gov.uk. https://www.gov.uk/government/publications/excise-notice-162-cider-production/excise-notice162-cider-production (retrieved September 14, 2015).

[16] IrastorzaIribas, A. and Dueñas Chasco, M.T. 2014. Microbiología de la sidra. In: Blanco Gomis, D. and Mangas Alonso, J.J. eds. La manzana y la sidra: bioprocesos, tecnologías de elaboración y control. Universidad de Oviedo, pp. 105-136.

[17] Jarvis, B., and Lea, A.G.H. 2000. "Sulphite binding in ciders." International Journal of Food Science and Technology35: 113-127 
[18] Justice Laws Website (Canada). 2015. "B.02.120. [S]. Cider" Food and Drug Regulations. http://laws-lois.justice.gc.ca/eng/regulations/c.r.c.,_c._870/page-64.html\#h-62

(retrieved September 14, 2015).

[19] Mangas Alonso, J.J., and Díaz Llorente, D. 2014. La manzana y su maduración. In: Blanco Gomis, D. and Mangas Alonso, J.J. eds.La manzana y la sidra: bioprocesos, tecnologías de elaboración y control. Universidad de Oviedo, pp. 11-104, 175-196, 235-252, y 299-318.

[20] Ministerio de Agricultura, Pesca, y Alimentación (España). 1992."Solicitud de Registro de la Denominación de Origen Protegida 'Sidra de Asturias." Asturias.es. http://www.asturias.es/Asturias/descargas/PDF_TEMAS/Agricultura/Alimentaci\%C3\%B3n/D.O .P\%20Sidra\%20de\%20Asturias.pdf (retrieved September 13, 2015).

[21] Ough, C. S. 1985. "Some Effects of Temperature and SO2 on Wine During Simulated Transport or Storage." American Journal of Enology and Viticulture 36 (1):18-22.

[22] Ough, C. S. 1987. "Use of PET Bottles for Wine." American Journal of Enology and Viticulture 38 (2):100-104.

[23] Ough, C. S., and C. E. Daudt. 1981. "Quantitative Determination of Volatile Amines in Grapes and Wines. I. Effect of Fermentation and Storage Temperature on Amine Concentrations." American Journal of Enology and Viticulture 32 (3):185-188.

[24] Polykeg. 2015. "T-Type Product Sheet." Polykeg. http://www.polykeg.it/files_cms/4news2/files/SmartLine_en.pdf (retrieved September 17, 2015).

[25] Reuss, RM, JE Stratton, DA Smith, PE Read, SL Cuppett, and AM Parkhurst. 2010. "Malolactic fermentation as a technique for the deacidification of hard apple cider." Journal of food science 75 (1):C74-C78.

[26] Robinson, Anthony L., Martha Mueller, Hildegarde Heymann, Susan E. Ebeler, Paul K. Boss, Peter S. Solomon, and Robert D. Trengove. 2010. "Effect of Simulated Shipping Conditions on Sensory Attributes and Volatile Composition of Commercial White and Red Wines." American Journal of Enology and Viticulture 61 (3):337-347.

[27] Rye, G.G., and Mercer, D.G. (2003). "Changes in headspace volatile attributes of apple cider resulting from thermal processing and storage". Food Research International36(2): 167

[28] Salih, AG, J-M Le Quérè, J-F Drilleau, and J Moreno Fernandez. 1990. "Lactic acid bacteria and malolactic fermentation in the manufacture of Spanish cider." Journal of the Institute of Brewing 96 (6):369-372.

[29] Sánchez, Ainoa, Gilles Revel, Guillaume Antalick, Mónica Herrero, Luis García, and Mario Díaz. 2014. "Influence of controlled inoculation of malolactic fermentation on the sensory properties of industrial cider." Journal of Industrial Microbiology \& Biotechnology 41 (5):853867. doi: 10.1007/s10295-014-1402-y.

[30] Scott, JA, and CH Swaffield. 1998. "Observations on the influence of temperature, dissolved oxygen and juice source on stored alcoholic cider flavour development." Food Biotechnology 12 (1-2):13-26.

[31] Swaffield, CH, JA Scott, and B Jarvis. 1997. "Observations on the microbial ecology of traditional alcoholic cider storage vats." Food microbiology 14 (4):353-361.

[32] Villamor, Remedios R., James F. Harbertson, and Carolyn F. Ross. 2009. "Influence of Tannin Concentration, Storage Temperature, and Time on Chemical and Sensory Properties of Cabernet Sauvignon and Merlot Wines." American Journal of Enology and Viticulture 60 (4):442-449. 